\title{
A Case of Telangiectatic Osteosarcoma in the Frontal Bone
}

\author{
Youhei TAKEUCHI, ${ }^{1}$ Shinya SONOBE, ${ }^{1}$ Naoya IWABUCHI, ${ }^{1}$ \\ Masahiro YosHIDA, ${ }^{1}$ and Teiji TOMINAGA ${ }^{2}$ \\ ${ }^{1}$ Department of Neurosurgery, Osaki Citizen Hospital, Osaki, Miyagi, Japan \\ ${ }^{2}$ Department of Neurosurgery, Tohoku University Graduate School of Medicine, Sendai, \\ Miyagi, Japan
}

\begin{abstract}
Telangiectatic osteosarcoma (TOS) is a subtype of osteosarcoma. TOS in the elderly and TOS in the skull are very rare. Here, we report a case of TOS in the frontal bone of an elderly patient. The patient was a 79-year-old woman who was identified as having a right frontal bone lesion. The patient was initially diagnosed with an intradiploic epidermoid cyst (IEC). A $60 \mathrm{~mm}$ cystic lesion with bone destruction appeared 5 years later, which enlarged over 2 months. The fluid in the cyst seemed to be blood that had lost its clotting ability. Tumor and the surrounding tissue were resected. The postoperative course was favorable. Postoperative magnetic resonance imaging (MRI) showed no evidence of residual lesions. There was no metastases. Histopathologically, the cyst wall was composed of fibrous connective tissue and did not contain epithelial components. There were no skin appendages and keratinized tissues in the lesion. Based on these findings, the diagnosis changed to aneurysmal bone cyst (ABC). Subsequent immunohistochemical examinations confirmed that the MIB-1 index was $50 \%$ in some sections and there were atypical cells showing osteogenic properties in other sections. Based on these results, the patient was finally diagnosed with TOS. The differential diagnoses for cystic lesion presenting bone destruction include TOS, ABC, and IEC. In case of cystic lesion with bone destruction, early diagnosis based on histopathological study is important and complete resection with surrounding tissues is required, given the possibility of TOS.
\end{abstract}

Keywords: telangiectatic osteosarcoma, cystic bone lesion with bone destruction, frontal bone

\section{Introduction}

Telangiectatic osteosarcoma (TOS) is a histologic subtype of osteosarcoma. ${ }^{1-4)}$ TOS is estimated to account for approximately $1 \%$ of all osteosarcomas. ${ }^{5)}$ Onset in the skull is very rare, and its clinical presentation is not well known. Here, we report a case of TOS in the frontal bone.

\section{Case Report}

The patient was a 79-year-old woman who was diagnosed with vertigo and was identified as having

Received November 4, 2019; Accepted July 16, 2020

Copyright $\subseteq 2021$ by The Japan Neurosurgical Society This work is licensed under a Creative Commons AttributionNonCommercial-NoDerivatives International License. a right frontal bone lesion (Fig. 1A and 1B). The patient was initially diagnosed with an intradiploic epidermoid cyst (IEC) and was followed up. Swelling of the right frontal region appeared 5 years later, which enlarged over 2 months, and the patient visited our institution for a medical examination.

Neurological examination found no abnormalities. An elastic soft mass measuring $6 \mathrm{~cm}$ in diameter was identified in the right frontal region. Blood tests showed no inflammatory reaction. Computed tomography (CT) revealed a cystic lesion measuring $60 \mathrm{~mm} \times 50 \mathrm{~mm} \times 47 \mathrm{~mm}$ in the right frontal bone. The bony structure of the lesion had disappeared, and dissociation between the inner and outer plates was observed in some sections (Figs. 1C and 1D). Magnetic resonance imaging (MRI) showed a homogeneous signal intensity within the lesion, and both T2-weighted imaging and diffusion-weighted imaging showed low signals. Contrast agents slightly enhanced 

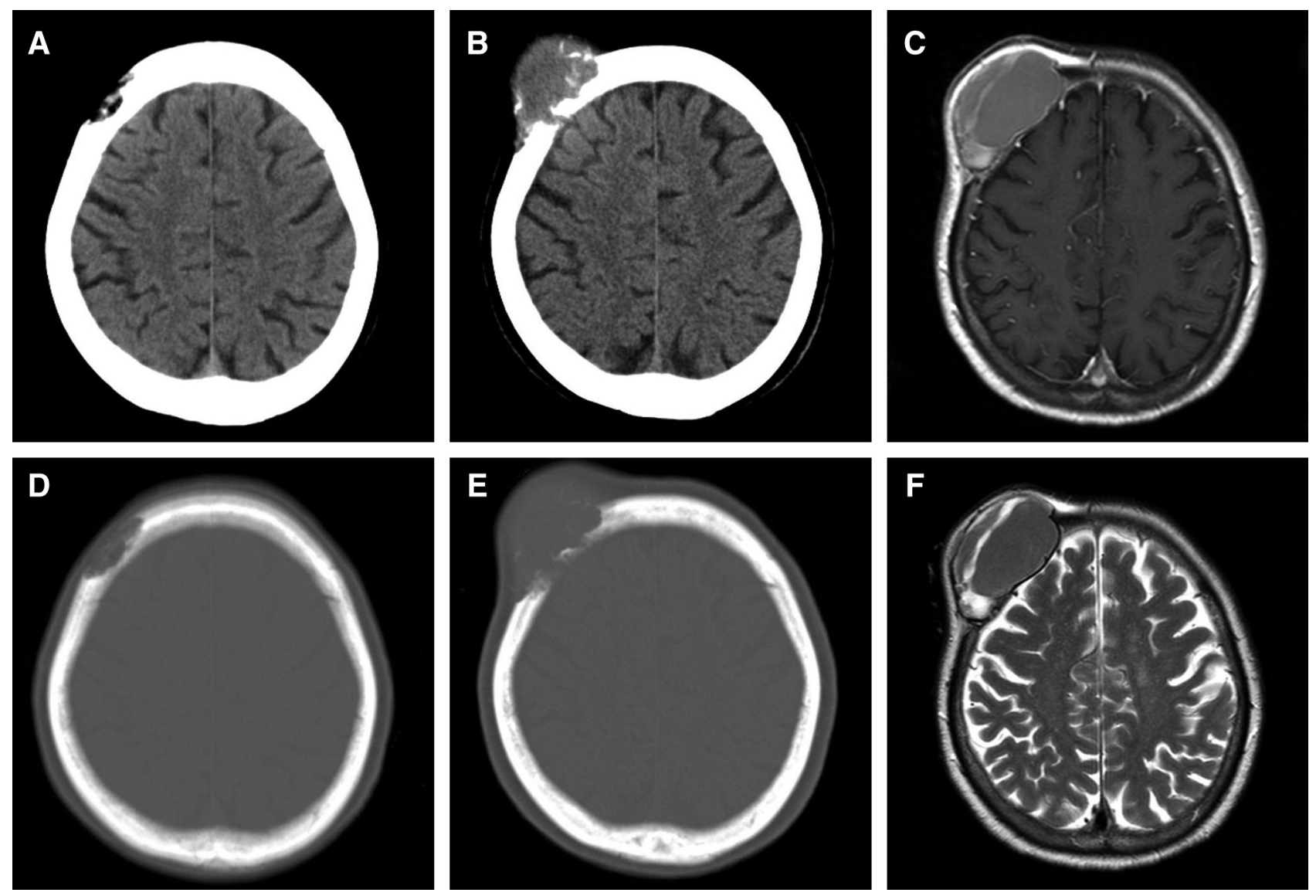

Fig. 1 (A and B) CT 5 years before operation. An intradiploic bone lesion in the right frontal bone was incidentally detected. (C and D) Preoperative CT showing a cystic lesion with bone destruction. (E and F) Preoperative MRI. (E) Contrast-enhanced T1-weighted imaging shows a slight enhancement in the cyst wall. (F) T2-weighted imaging shows a homogeneous signal intensity within the lesion. CT: computed tomography, MRI: magnetic resonance imaging.

the signal intensity of the cyst wall and the surrounding diploe. The boundary between the cyst and periosteum was clear, and the margins were smooth. The border of the dura mater was not clear (Figs. $1 \mathrm{E}$ and $1 \mathrm{~F}$ ). The fluid in the cyst obtained by percutaneous puncture was dark red and serous, which did not contain platelets and did not clot. Levels of hemoglobin, total protein, albumin, and glucose were slightly lower, those of total bilirubin and lactate dehydrogenase were higher, and those of sodium, potassium, chloride, aspartate aminotransferase, alanine aminotransferase, blood urea nitrogen, creatinine, partial pressure of oxygen, and partial pressure of carbon dioxide were equivalent to venous blood. Other blood cell counts were normal; however, platelets were undetectable and the sample did not clot. The sample seemed to contain blood that had lost its clotting ability.

The patient underwent tumor resection based on the diagnosis of IEC. A loose connective tissue layer beneath the galeal aponeurosis was dissected, and the flap was everted, leaving a periosteum on the surface of the tumor (Fig. 2A). There was no macroscopic tumor infiltration in the flap. The tumor was punctured and aspirated, causing the cyst to collapse. The contents were dark red serum. The tumor adhered to the surrounding bone and was bluntly detached. A navigation system confirmed the range of normal bone tissue, and the surrounding bone was resected in the shape of a doughnut (Fig. 2B). The tumor tightly adhered to the dura mater, and detachment was not attempted. With the surrounding normal dura mater roundly incised, the tumor was resected together with the dura mater (Fig. 2C). There was no macroscopic tumor infiltration on the inner surface of the dura mater (Fig. 2D). Duraplasty was performed with an artificial dura mater, and cranioplasty was performed with an artificial bone (Fig. 2E). The patient followed an uneventful course without developing any complications, and the 

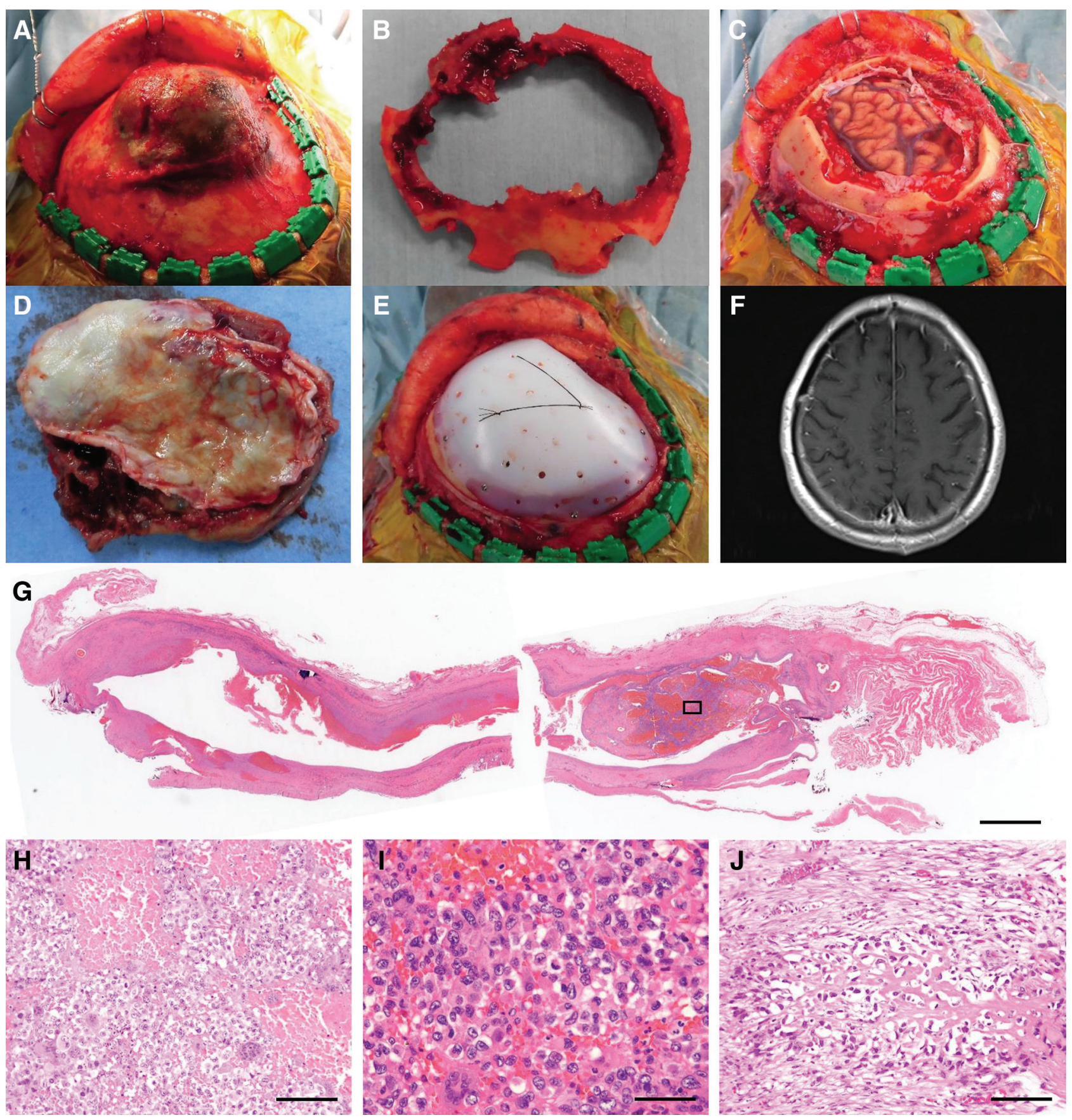

Fig. 2 (A-E) Intraoperative photographs. (F) Postoperative MRI. Histopathological findings of the resected tumor. (G-I) Hematoxylin and eosin staining. (J) Ki67 staining. (A) The skin flap was everted, leaving a periosteum on the surface of the tumor. (B) The surrounding bone was resected in the shape of a doughnut. (C) The tumor was resected together with the dura mater. (D) Dura mater side of the resected tumor. No macroscopic tumor infiltration was found on the inner surface of the dura mater. (E) Duraplasty was performed with artificial dura mater, and cranioplasty was performed with artificial bone. (F) No residual lesions is observed. (G) Cross-section of the entire cyst. The cyst wall is composed of fibrous connective tissue. Original magnification: $\times 10$. Scale bar: $4 \mathrm{~mm}$. (H) The site indicated by the box in G. Highly atypical cells and intratumoral hemorrhage suggesting malignancy are observed. Original magnification: $\times \mathbf{2 0 0}$. Scale bar: $100 \mu \mathrm{m}$. (I) The highly magnified picture of $\mathrm{H}$. Nuclei of atypical cells are irregular and different in size, and nucleoli of them are enlarged. Original magnification: $\times 400$. Scale bar: $50 \mu \mathrm{m}$. (J) The septum of the cyst in another section. Atypical cells with osteogenic properties are observed in other sections. Original magnification: $\times 200$. Scale bar: $100 \mu \mathrm{m}$. MRI: magnetic resonance imaging. 
patient was discharged 12 days after the surgery. Postoperative MRI showed no evidence of residual lesions (Fig. 2F). A systemic search including contrast-enhanced CT and positron emission tomography performed in the subsequent follow-up revealed no metastases.

Histopathologically, the cyst wall was composed of fibrous connective tissue and did not contain epithelial components. The cyst has no septum structure. The content was mainly red blood cells; there were no skin appendages and keratinized tissues (Fig. 2G). The bone structure has no abnormal arrangement. Based on these findings, aneurysmal bone cyst (ABC) was also considered as a differential diagnosis. Subsequent histopathological examination revealed that there were highly atypical cells with intratumoral hemorrhage in some sections (Fig. $2 \mathrm{H}$ and 2I) and atypical cells showing osteogenic properties in other sections (Fig. 2J). Based on these results, the patient was finally diagnosed with TOS. Predominance of cystic lesion made the diagnosis TOS rather than other forms of osteosarcoma. Subcutaneous and dura mater infiltration were not observed.

\section{Discussion}

TOS is a honeycomb-like cystic lesion composed of a cyst wall and septa. The septum is predominantly fibrous connective tissue and contains atypical cells. Atypical cells produce abnormal bone and osteoid. $\left.{ }^{6}\right)$ Spaces between septa are filled with blood that has lost its ability to clot; it presents fluid-fluid level. As with conventional osteosarcoma, the disease is more common in adolescent boys and occurs more commonly in the distal femoral and proximal tibial metaphysis. Onset in the elderly and in the skull are very rare. Given the susceptible age, an association between bone growth and onset has been suggested. The cause of primary TOS is unknown; fibrous dysplasia, radiation, and osteomyelitis are known as the cause of secondary TOS. TOS-specific gene abnormalities have not been reported. The tumor destroys surrounding bone tissue and enlarges within several months. Extraosseous involvement into subcutaneous or dura mater is not common. Distant metastases are observed in $10 \%$ of patients, and distant metastases to the lungs are reportedly more common than metastases to other locations. ${ }^{7)}$ As risk factors for distant metastases, onset in patients aged $\geq 30$ years and large tumor size have been identified. ${ }^{7,8)}$ Treatment is complete resection of the primary tumor and chemotherapy to control metastases.

The differential diagnoses for TOS include ABC and IEC. Both are cystic lesions with bone destruction; imaging findings are similar to those of TOS. The characteristics of TOS, ABC, and IEC are shown in Table 1. ABC is a honeycomb-shaped cystic lesion composed of a cyst wall and septa similar to TOS. The cyst cavity is filled with blood that has lost its ability to clot; it presents fluid-fluid level. ${ }^{9,10)}$ Histological findings for $\mathrm{ABC}$ are very similar to those of TOS, but differ in that ABC does not contain atypical cells. The incidence is high in patients aged $\leq 20$ years, and incidence in the elderly is rare. ABC commonly occurs in the metaphysis of long tubular bones and the pelvis; it rarely occurs in the skull. ${ }^{11)}$ Primary ABC accounts for approximately $70 \%$ of patients, and approximately $70 \%$ of these patients express CDH11-USP6-fused genes through the reciprocal chromosomal translocation $\mathrm{t}(16 ; 17)(q 22 ; \mathrm{p} 13)$. In secondary ABC, abnormalities in the CDH11 and USP6 genes are not observed, and the pathology appears to differ from primary disease. As precursor lesions, bone tumors such as giant cell tumors of the bone (19-39\%), chondroblastoma, osteoblastoma, fibrous dysplasia, nonossifying fibroma, and simple bone cysts have been identified. Although rare, there were some reports on ABC secondary to trauma. Impairment of venous return in the cancellous bone can increase $\mathrm{ABC}$ rapidly. There was no report on extraosseous infiltration. Some reports describe malignant transformation to sarcoma after more than 5 years. IEC is a cystic lesion arising from stratified squamous epithelium with keratinization. The contents of cyst include keratin and cholesterol. It is more common between the ages of 40 and 60 years and affects the frontal, parietal, and occipital bones. There are over 200 case reports on IEC. Aberrant epidermal cells in the fetus are considered to be the origin. ${ }^{12)}$ There are some reports on acquired onset due to trauma. IEC destroys surrounding tissues and enlarges slowly. Malignant transformation to squamous cell carcinoma has been observed in $2.4 \%$ of patients. ${ }^{13)}$ Malignant transformation results in rapid enlargement. In our case, the cyst wall was shown to be mainly composed of fibrous connective tissue in the pathohistological examination, and immunohistological examination confirmed atypical cells with abnormal osteogenesis in the cyst wall. Based on these findings, our patient ruled out $\mathrm{ABC}$ without genetic test and was finally diagnosed with TOS.

Since the progression of TOS is rapid, early diagnosis is required. ABC must be resected if enlarging and should be followed-up if not. Given the similarities in imaging findings between TOS and $\mathrm{ABC}$, pathological biopsy is required for a conclusive diagnosis. IEC must be resected in symptomatic cases and should be followed-up if not. 
Table 1 Differentiation of cystic lesions presenting bone destruction

\begin{tabular}{|c|c|c|c|}
\hline & TOS & $\mathrm{ABC}$ & IEC \\
\hline Tissue of cyst wall & Fibrous connective tissue & Fibrous connective tissue & $\begin{array}{l}\text { Stratified squamous } \\
\text { epithelium }\end{array}$ \\
\hline Component of cyst wall & $\begin{array}{l}\text { Atypical cells forming bone } \\
\text { and osteoid }\end{array}$ & $\begin{array}{l}\text { Fibroblasts and osteoclast- } \\
\text { type giant cells }\end{array}$ & Keratinization \\
\hline Atypical cell & $(+)$ in the septa & $(-)$ & $(-)$ \\
\hline Content & Blood without ability to clot & Blood without ability to clot & Keratin, cholesterol \\
\hline \multicolumn{4}{|l|}{ MRI } \\
\hline Content & $\begin{array}{l}\text { Heterogeneous intensity, } \\
\text { fluid-fluid level }\end{array}$ & $\begin{array}{l}\text { Heterogeneous intensity, } \\
\text { fluid-fluid level }\end{array}$ & $\begin{array}{l}\text { T1WI: low, T2WI: high, } \\
\text { DWI: high }\end{array}$ \\
\hline Cyst wall & Gd-enhancement (+) & Gd-enhancement (+) & Gd-enhancement (+) in $25 \%$ \\
\hline \multicolumn{4}{|l|}{ Mechanism } \\
\hline Primary & Unknown & $\mathrm{t}(16 ; 17)(\mathrm{q} 22 ; \mathrm{p} 13)$ is suggested & $\begin{array}{l}\text { Ectopic inclusion of } \\
\text { epithelial cells }\end{array}$ \\
\hline Secondary & $\begin{array}{l}\text { Fibrous dysplasia, radiation, } \\
\text { osteomyelitis }\end{array}$ & Tumor, trauma & Trauma \\
\hline \multicolumn{4}{|l|}{ Susceptible } \\
\hline Age & $\begin{array}{l}10-20 \\
\text { (30s in TOS in skull) }\end{array}$ & $<20$ & $40 s-60 s$ \\
\hline Sex & Male & No difference & No difference \\
\hline Site & Femur, tibia, humerus, pelvis & $\begin{array}{l}\text { Femur, tibia, humerus, } \\
\text { pelvis, spine }\end{array}$ & $\begin{array}{l}\text { Frontal bone, parietal bone, } \\
\text { occipital bone }\end{array}$ \\
\hline Malignant transformation & - & $\begin{array}{l}\text { Sarcoma (a few cases in the } \\
\text { past) }\end{array}$ & $\begin{array}{l}\text { Squamous cell carcinoma } \\
(2.4 \%)\end{array}$ \\
\hline Progression speed & Rapidly & Slowly (rapidly at times) & Slowly \\
\hline Extraosseous invasion & $(+)$ & $(-)$ & $(-)$ \\
\hline Metastasis & Lung & - & - \\
\hline Treatment & Removal, chemotherapy & Removal & Removal \\
\hline
\end{tabular}

ABC: aneurysmal bone cyst, DWI: diffusion-weighed imaging, IEC: intradiploic epidermoid cyst, MRI: magnetic resonance imaging, TOS: telangiectatic osteosarcoma.

Although cystic lesions of the skull tend to be diagnosed as IEC from a frequency perspective, pathological biopsy is important given the possibility of TOS.

The prognosis of skull TOS has not been elucidated. Even if the patient is completely resected by surgery, additional treatment such as radiation therapy or chemotherapy may be necessary. In the present case, no additional treatment was given because the patient was older and it was unclear what treatment was effective. This issue needs further study.

Complete resection is the standard treatment for cystic lesions presenting with bone destruction because residual TOS, ABC, and IEC lead to recurrence. All of these lesions can involve infiltration into diploe and must be resected with adequate margins. TOS may infiltrate into periosteum, and IEC after malignant transformation may infiltrate periosteum and dura mater ${ }^{14,15)}$; hence, these lesions should be resected including surrounding tissue. In this patient, the loose connective tissue beneath the galeal aponeurosis was dissected, and the surrounding normal bone and dura mater were resected all together.

Seven patients with TOS in the skull have been reported, including our patient. ${ }^{16-20)}$ The details are shown in Table 2. In the described reports, cystic lesions were found on imaging or histological findings. TOS that arises in long tubular bones are frequently observed in patients between the ages of 10 and 19 years, whereas more than half of TOS in the skull occurs over the age of 40. Notably, there were two patients with Paget's disease of bone. TOS secondary to Paget's disease of bone was not reported except these two cases, whereas conventional osteosarcoma is known to occur secondarily in Paget's disease of bone. Thus, TOS 
Table 2 Summary of literature cases of telangiectatic osteosarcoma in the skull

\begin{tabular}{|c|c|c|c|c|c|c|c|}
\hline Authors & Year & Age/sex & Lesion & TOS type & Symptoms & Treatment & Reference \\
\hline Huvos et al. & 1982 & n.d. & n.d. & n.d. & n.d. & n.d. & [16] \\
\hline Huvos et al. & 1982 & n.d. & n.d. & n.d. & n.d. & n.d. & {$[16]$} \\
\hline Donato et al. & 1997 & 75 , Female & Parietal bone & Secondary (PD) & $\begin{array}{l}\text { Swelling, } \\
\text { hemiparesis }\end{array}$ & Removal & [17] \\
\hline $\begin{array}{l}\text { Whitehead } \\
\text { et al. }\end{array}$ & 1998 & 48, Male & $\begin{array}{l}\text { Sphenoid } \\
\text { bone }\end{array}$ & Primary & $\begin{array}{l}\text { Swelling, pain, } \\
\text { blurred vision }\end{array}$ & $\begin{array}{l}\text { Removal and } \\
\text { chemoradiation }\end{array}$ & [18] \\
\hline Merino et al. & 1999 & 79, Female & Frontal bone & Secondary (PD) & Swelling, pain & Partial removal & [19] \\
\hline $\begin{array}{l}\text { Patibandla } \\
\text { et al. }\end{array}$ & 2011 & 30, Female & $\begin{array}{l}\text { Occipital } \\
\text { bone }\end{array}$ & Primary & $\begin{array}{l}\text { Headache, } \\
\text { nausea, } \\
\text { vomiting }\end{array}$ & $\begin{array}{l}\text { Removal and } \\
\text { chemoradiation }\end{array}$ & {$[20]$} \\
\hline Present case & 2019 & 79, Female & Frontal bone & Primary & Swelling & Removal & - \\
\hline
\end{tabular}

n.d.: not described, PD: Paget's disease of bone, TOS: telangiectatic osteosarcoma.

arising in the skull differs in clinical presentation from TOS arising in long tubular bones. This difference might indicate different etiologies. This assessment is conducted on a small number of patients, and further study in a larger population is required. The case described herein was an elderly patient with TOS in the frontal bone that rapidly increased 5 years after the identification of the lesion. Although no histological evidence was given, our case could have been a secondary TOS originating from precursor lesions.

\section{Conclusions}

We report a case of TOS in the frontal bone. Differential diagnosis of cystic lesions of the skull with bone destruction includes TOS, ABC, and IEC. It is difficult to make a diagnosis based only on image findings. Early diagnosis based on histopathological study is important, and complete resection that includes surrounding tissues is the standard treatment.

\section{Informed Consent}

Informed consent has been obtained from the patient for this report.

\section{Acknowledgments}

We thank Dr. Kazuhiro Sakamoto for his helpful advice on histological findings. This study was not supported by any funding.

\section{Conflicts of Interest Disclosure}

All authors have no conflict of interest.

\section{References}

1) Rosen G, Huvos AG, Marcove R, Nirenberg A: Telangiectatic osteogenic sarcoma. Improved survival with combination chemotherapy. Clin Orthop Relat Res 164-173, 1986

2) Matsuno T, Unni KK, McLeod RA, Dahlin DC: Telangiectatic osteogenic sarcoma. Cancer 38: 2538-2547, 1976

3) Farr GH, Huvos AG, Marcove RC, Higinbotham NL, Foote FW: Telangiectatic osteogenic sarcoma. A review of twenty-eight cases. Cancer 34: 11501158, 1974

4) Bacci G, Ferrari S, Ruggieri P, et al.: Telangiectatic osteosarcoma of the extremity: neoadjuvant chemotherapy in 24 cases. Acta Orthop Scand 72: 167-172, 2001

5) Nakashima Y: Osteosarcoma (2); telagiectatic osteosarcoma and intraosseous well-differentiated osteosarcoma. Clinical Orthopaedic Surgery, 2009

6) Murphey MD, wan Jaovisidha S, Temple HT, Gannon FH, Jelinek JS, Malawer MM: Telangiectatic osteosarcoma: radiologic-pathologic comparison. Radiology 229: 545-553, 2003

7) Yin JQ, Fu YW, Xie XB, et al.: Telangiectatic osteosarcoma: Outcome analyses and a diagnostic model for differentiation from aneurysmal bone cyst. $J$ Bone Oncol 11: 10-16, 2018

8) Huang $\mathrm{X}$, Zhao J, Bai J, et al.: Risk and clinicopathological features of osteosarcoma metastasis to the lung: a population-based study. J Bone Oncol 16: 100230, 2019

9) Devi P, Thimmarasa V, Mehrotra V, Agarwal M: Aneurysmal bone cyst of the mandible: a case report and review of literature. J Oral Maxillofac Pathol 15: 105-108, 2011

10) Jaffe HL, Lichtenstein L: Solitary unicameral bone cyst: with emphasis on the roentgen picture, the pathologic appearance and the pathogenesis. JAMA Surgery 44: 1004-1025, 1942 
11) Ruiter DJ, van Rijssel TG, van der Velde EA: Aneurysmal bone cysts: a clinicopathological study of 105 cases. Cancer 39: 2231-2239, 1977

12) Sano K: Intracranial dysembryogenetic tumors: pathogenesis and their order of malignancy. Neurosurg Rev 24: 162-167; discussion 168-170, 2001

13) Michael LM, Moss T, Madhu T, Coakham HB: Malignant transformation of posterior fossa epidermoid cyst. Br J Neurosurg 19: 505-510, 2005

14) Arko L, Berry CT, Desai AS, Weaver M: Intradiploic epidermoid tumors of the cranium: case report with review of the literature. J Neurol Surg A Cent Eur Neurosurg 78: 167-179, 2017

15) Agarwal S, Rishi A, Suri V, et al.: Primary intracranial squamous cell carcinoma arising in an epidermoid cyst--a case report and review of literature. Clin Neurol Neurosurg 109: 888-891, 2007

16) Huvos AG, Rosen G, Bretsky SS, Butler A: Telangiectatic osteogenic sarcoma: a clinicopathologic study of 124 patients. Cancer 49: 1679-1689, 1982
17) Donato G, Lavano A, Volpentesta G, et al.: Telangiectatic osteosarcoma of the skull. A post-Paget case. Clin Neuropathol 16: 201-203, 1997

18) Whitehead RE, Melhem ER, Kasznica J, Eustace S: Telangiectatic osteosarcoma of the skull base. AJNR Am J Neuroradiol 19: 754-757, 1998

19) Merino S, Arrazola J, Saiz A, Blanco JA, Ortega L: Post-Paget telangiectatic osteosarcoma of the skull. Skeletal Radiol 28: 470-472, 1999

20) Patibandla MR, Uppin SG, Thotakura AK, Panigrahi MK, Challa S: Primary telangiectatic osteosarcoma of occipital bone: a case report and review of literature. Neurol India 59: 117-119, 2011

Corresponding author: Masahiro Yoshida, MD, PhD Department of Neurosurgery, Osaki Citizen Hospital, 3-8-1 Furukawahonami, Osaki, Miyagi 989-6183, Japan.

e-mail: myoship1964@gmail.com 